\title{
Quantum mechanical effects in the Coulomb interaction of electrons which are localized in opposite double electron layers
}

\author{
Lukiyanets B., Matulka D. \\ Lviv Polytechnic National University \\ 12 S. Bandera str., 79013, Lviv, Ukraine
}

(Received 5 November 2016)

\begin{abstract}
The Coulomb interaction between electrons of opposite double layers in nanostructures with taking into account discrete electron states is theoretically studied. It is shown that at a certain ratio between the width of double layers and distances between them, the Coulomb interaction is sensitive to the energy states of interacting electrons.
\end{abstract}

Keywords: Coulomb interaction, double electron layer, quantum mechanical effect.

2000 MSC: $81 \mathrm{~V} 99$

UDC: 53.043

\section{Introduction}

It is known that at a contact of two different condensed systems the properties of the surface layer of each system are changed. Usually, the interfacial region is electrically neutral. Efforts of such heterogeneous system to minimize Gibbs energy lead to spatial nonuniform, different in sign separation of charged particles, called double electron layer (DEL). Such layer, as well as created by it potential, plays an important role in adsorption, electrokinetic and electrocapillary phenomena. Materials with DEL allow us to create essentially new, different from the traditional, high-capacity electrical energy storage capacitors - supercapacitors [1]. Therefore, research of DEL, the search for a deeper understanding of the phenomenon in it are relevant. An electric double layer can be seen, for example, in a pore filled with electrolyte. In the longitudinal section of such pore along its diameter, we get a pair of closely spaced double layer with potential, presented in (Fig. 1). We see that each of them resembles known from semiconductor physics inversion layer [2]. An electron is confined in it and, as the effective size of the layer is of nanometer scale, this leads to discrete energy levels. Interactions of neighboring surface electron layers in aqueous solutions were and are the subject of a number of studies. To do this Derjagin-Landau-Vervey-Overbeek theory (DLVO) is widely used, which takes into account both electrostatic and van der Waals interaction of ions in the solution [3]. The change of electrostatic repulsion into attraction due to the van der Waals interactions when charged double layers get closer together was one of the predictions of this theory. However, it was established that experimentally measured force of repulsion at short distances cannot be explained within DLVO [4]. One of the reasons why we cannot explain this is the use of the Boltzmann distribution in the determination of concentration of ions. This distribution requires that the electric potential vanishe with a movement from the changed surface, and the concentration of ions coincides with the bulk concentration. In fact, when the distance between the layers is shortened, i.e. when their potentials substantially overlap, the concentration of ions in the middle between double layers differs from those for bulk case. In other words, the DLVO theory, which is based on the Boltzmann distribution cannot accurately describe the electrostatic repulsion in this task. Therefore, the search for more adequate description of such interaction continues. For example, in [5] for describing the interaction of neighboring double electrical layers, a new theoretical model that avoids the Boltzmann distribution, but uses the Poisson and Nernst equations and conservation of mass was considered. The purpose of proposed paper is to attract attention to the peculiarities of the interaction of double electrical layers in a nanostructure caused by an effect of quantum mechanical nature. 


\section{Theoretical method}

It is known that Coulomb's law is formulated for point charges. "Point charge" is an idealization. A criterion of applicability of this approach is $R \ll r(R$ is characteristic dimension of interacting charges separated by the distance $r$ ). In the certain cases, consideration of even a small size of the charge causes corrections to the results obtained in the "point charge" approach. For example, if a very small uniformly charged body is placed into electrostatic field $V(\boldsymbol{r})$, its potential energy is [6]

$$
U(\boldsymbol{r})=V(\boldsymbol{r})+\frac{r_{0}^{2}}{6} \nabla^{2} V(\boldsymbol{r})+\ldots
$$

where $\boldsymbol{r}$ is the location of the charge, and $r_{0}$ is its very small radius. The second term in this equation can be regarded as a perturbation in the result of "point charge" approach. In the cited paper, the perturbations of $1 s$ - and $2 p$-states of the hydrogen atom were considered. From the standpoint of quantum mechanics, probabilistic nature of electron localization, in fact, denies "point charge" approach. Let us take into account this fact in considering Coulomb interaction between two electrons which are localized at opposite double electron layers. For this purpose, consider a one-dimensional case with potential, shown in Fig. 1a. As we pursued a qualitative picture of the interaction, we consider the system of two symmetrical infinitely deep wells and widths $a$ instead the true potential (see Fig. $1 b$ ).

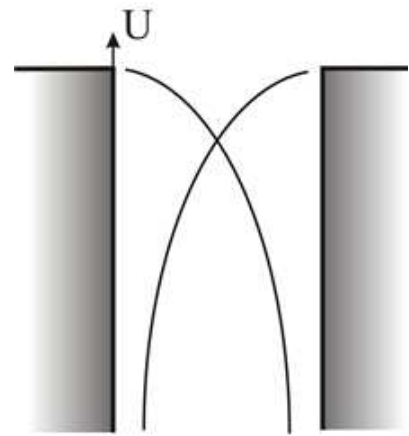

$a$

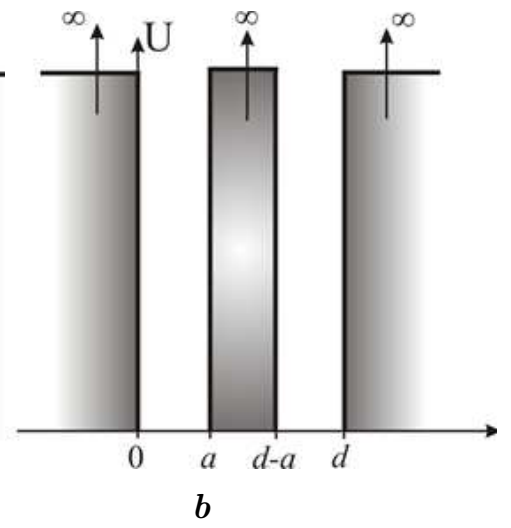

Fig. 1. Real $(a)$, and simulated one-dimensional potential with double electron (or inversion) layers (b).

$$
E_{n}=\frac{\hbar^{2} \pi^{2}}{2 m a^{2}} n^{2}
$$

The question arises: Does the Coulomb interaction of electrons of opposite wells depend on their quantum states? The wave functions (2) in the form $\left|\psi_{n}\left(x_{i}\right)\right|^{2}(i=1,2)$ determine the probability of an electron in the quantum state $n$ with the coordinate $x$. Then $e\left|\psi_{n}\left(x_{i}\right)\right|^{2}$ determines the charge probability in the same state and in the same point. Then the potential energy of the Coulomb interaction $V_{n m}$ of electrons of opposite wells, which are in the quantum states $n, m$, can be presented as the integral:

$$
V_{n m}=\int_{0}^{a} d x_{1} \int_{d-a}^{d} d x_{2} \frac{1}{4 \pi \varepsilon_{0}} \frac{e\left|\psi_{n}\left(x_{1}\right)\right|^{2} e\left|\psi_{m}\left(x_{2}\right)\right|^{2}}{\left|x_{1}-x_{2}\right|}
$$

or taking into account $(2)$

$$
V_{n m}=\frac{4}{a^{2}} \int_{0}^{a} d x_{1} \int_{d-a}^{d} d x_{2} \frac{1}{4 \pi \varepsilon_{0}} \frac{e^{2} \sin ^{2}\left(\frac{n \pi}{a} x_{1}\right) \sin ^{2}\left(\frac{m \pi}{a}\left(x_{2}-d+a\right)\right)}{\left|x_{1}-x_{2}\right|}
$$




\section{Discussion}

We have calculated the dependence $\delta_{n m}(a)=\left|1-\frac{V_{n m}(a)}{V_{11}(a)}\right| \cdot 100 \%$, which characterizes the relative deviation of the potential energy $V_{n m}(a)$ of interaction of electrons in the states $n, m$ from the analogous interaction of electrons in the ground state $V_{11}(a)$ in both wells depending on their widths $a$. As we considered a fixed width of the pore $(d=4 \mathrm{~nm})$, the expansion of the well $a$, on the one hand, increases the region of localization of electrons, and, on the other hand, reduces the distance between them. In other words, for electrons in narrower wells, the "point charge" approach is more acceptable than it is for in wider ones. Such dependences, presented in Fig. $2 a$, show that for both electrons in the 1st excited state $(n=m=2)$ the relative deviation $\delta_{22}(a)=\left|1-\frac{V_{22}(a)}{V_{11}(a)}\right| \cdot 100 \%$ varies from almost zero at $a=0.1 \mathrm{~nm}$ to $\sim 3 \%$ at $a=1.5 \mathrm{~nm}$. For an electron in the ground state in one of the well and for the other one in excited state in the other (opposite) well, $\delta_{12}(a)=\left|1-\frac{V_{12}(a)}{V_{11}(a)}\right| \cdot 100 \%$ in the same range of variation $a$ takes values from 0 to $1.5 \%$. Other cases can be seen in Fig. $2 a$.

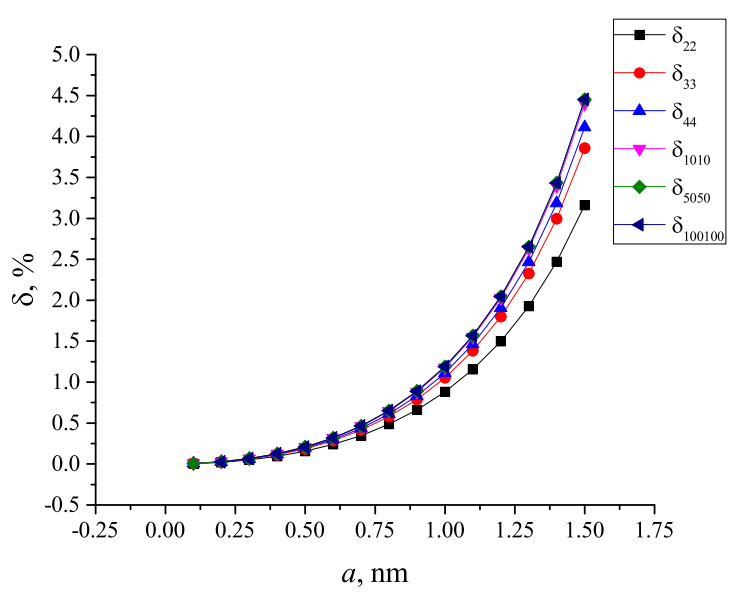

$a$

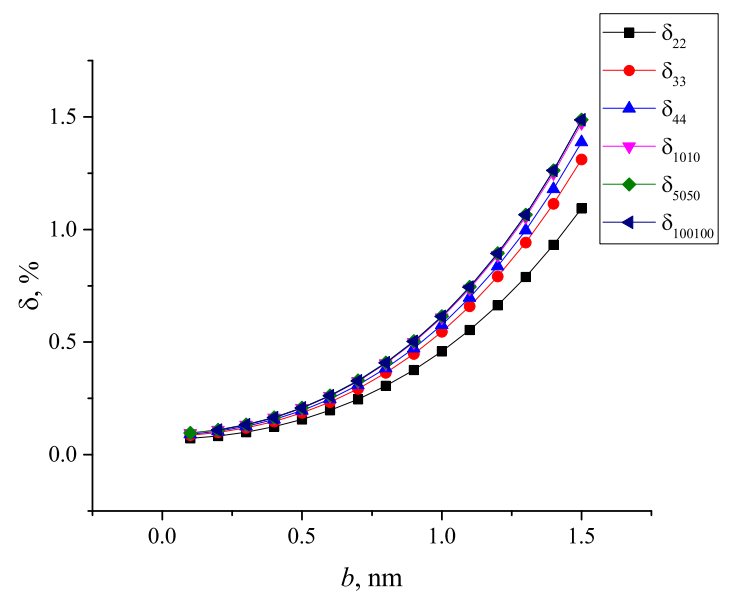

$b$

Fig. 2. Dependences of relative deviation $\delta_{n m}(a)=\left|1-\frac{V_{n m}(a)}{V_{11}(a)}\right| \cdot 100 \%$ on the width $a$ of the wells (symmetric case) $(a), \delta_{n m}(b)=\left|1-\frac{V_{n m}(b)}{V_{11}(b)}\right| \cdot 100 \%$ on the width $b$ of the well (width $a$ of the opposite well is fixed, $a=0.5 \mathrm{~nm}$; assymmetric case $)(b)$.

Thus, for the narrower wells (i.e. when electrons are almost points with dimensions of the well), the electronic states practically do not manifest themselves. With the increase in widths of wells, the potential energy depends on the energy states of interacting electrons, and as a consequence, the greater deviation $\delta_{i j}$ is. It is the main qualitative result of the problem. Obtaining of the quantitative results of the problem requires consistent consideration in the framework of a more real model (finite potential in the wells, tunneling, exchange effects, etc.).

A similar problem of the asymmetric wells, i.e. a case of the fixed width a of one of the wells ( $a=$ const $)$ and the width $b$ of the other well which varies in a certain range, is reduced to the following integration

$$
V_{n m}=\frac{4}{a b} \int_{0}^{a} d x_{1} \int_{d-b}^{d} d x_{2} \frac{1}{4 \pi \varepsilon_{0}} \frac{e^{2} \sin ^{2}\left(\frac{n \pi}{a} x_{1}\right) \sin ^{2}\left(\frac{m \pi}{b}\left(x_{2}-d+b\right)\right)}{\left|x_{1}-x_{2}\right|} .
$$

The obtained dependences $\delta_{n m}(b)=\left|1-\frac{V_{n m}(b)}{V_{11}(b)}\right| \cdot 100 \%$ at $a=0.5 \mathrm{~nm}$ and variable $b$ are presented in Fig. $2 b$. They have the same behavior as in the case of symmetric problem. 


\title{
4. Conclusions
}

The obtained effect can have some manifestation in physical phenomena. In particular, the described interaction affects the degree of localization of double (or inverse) electron layer, which is closely connected with such characteristics as the capacitance. Therefore, we can assume that the value of capacitance can be controlled by excitation of the electron subsystem. On the other hand, the effect may be important in the self-consistent calculations of the electronic spectrum in nanostructures. Coulomb repulsion of electrons of opposite wells in the case of fixed pore size leads to higher localization of electrons near the walls of the pore, i.e. in terms of our model to reduction of the width of the pore, and as a result, to change in wave functions. These functions, in their turn, change the potential of the problem and, therefore, the wave functions are being changed again, and so on. This procedure is to be iterated as long as the results of these iterations do their specified accuracy.

[1] Mallika S., Saravana Kumar R. Review on Ultracapacitor-Battery Interface for Energy Management System. International Journal of Engineering and Technology, 3, 37-43 (2011).

[2] Grundmann M. The Physics of Semiconductors. Springer: Berlin-Heidelberg, 96 (2006).

[3] Verwey E. J., Overbeek J. Th. G. The Theory of Stability of Liophobic Colloids. Elsevier, Amsterdam (1948).

[4] Viani B. E., Low P. F., Roth C. B. Direct measurement of the relation between interlayer force and interlayer distance in the swelling of montmorillonite. J. Colloid Interface Sci. 96, 229-244 (1983).

[5] Ren C.L., Hu Y., LiD., Werner C. A new model for the electrical double layer interaction between two surfaces in aqueous solutions. The Journal of Adhesion. 80, 831-849 (2004).

[6] Lim Y.-K. Problems and solutions on atomic, nuclear, and particle physics. World Scientific Singapore, 727 (2000).

[7] Davydov A. S. Quantum Mechanics. Pergamon Press (1965).

\section{Квантово-механічні ефекти в кулонівській взаємодії електронів локалізованих у протилежних подвійних електричних шарах}

\author{
Лукіянець Б. А., Матулка Д. В. \\ Національний університет “Львівсъка політехніка" \\ вул. С. Бандери, 12, 79013, Львів, Украӥна
}

Теоретично досліджено кулонівську взаємодію між електронами в протилежних подвійних шарах у наноструктурах з урахуванням дискретних електронних станів. Показано, що за певного співвідношення між шириною подвійних шарів і відстанню між ними кулонівська взаємодія чутлива до енергетичних станів взаємодіючих електронів.

Ключові слова: кулонівсъка взаємодія, подвійний електричний шар, квантовомеханічний ефект.

2000 MSC: $81 \mathrm{~V} 99$

УдК: 53.043

Mathematical Modeling and Computing, Vol.3, No. 2, pp.173-176 (2016) 